
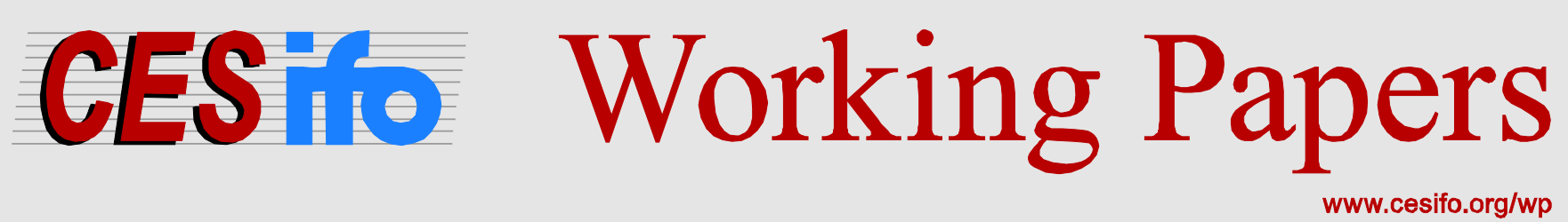

\title{
Moral Hazard and Bargaining over Incentive Contracts
}

\author{
Marcus Dittrich \\ Silvio Städter
}

CESIFO WORKING PAPER NO. 4920

CATEGORY 4: LABOUR MARKETS

JULY 2014

An electronic version of the paper may be downloaded

- from the SSRN website:

- from the RePEc website:

- from the CESifo website:

WWW.SSRN.com

Www.RePEc.org

www.CESifo-group.org/wp

\section{CESifo}




\title{
Moral Hazard and Bargaining over Incentive Contracts
}

\begin{abstract}
This paper analyses bargaining over an incentive compatible contract in a moral hazard framework. We introduce the Kalai-Smorodinsky bargaining solution and compare the outcome with the commonly applied Nash solution. Whether worker's effort is higher in the Nash or the Kalai-Smorodinsky solution depends on the agents. bargaining power. If agents have equal bargaining power, the contract in the Kalai-Smorodinsky solution yields a more efficient outcome and induces more effort. The social planner can mitigate inefficiencies arising in both bargaining solutions from the moral hazard problem and even achieve the firstbest outcome by allocating the agents' bargaining power. If raising the worker's bargaining power is necessary to achieve the first-best solution, this increase must be higher in the Nash solution than in the Kalai-Smorodinsky solution.
\end{abstract}

JEL-Code: C710, D820, J410.

Keywords: incentive contracts, moral hazard, Nash bargaining solution, Kalai-Smorodinsky solution, bargaining power.

Marcus Dittrich

Chemnitz University of Technology

Department of Economics

and Business Administration

Germany-09107 Chemnitz

marcus.dittrich@wirtschaft.tu-

chemnitz.de

\author{
Silvio Städter \\ University of Regensburg \\ Department of Economics \\ Germany-93040 Regensburg \\ silvio.staedter@wiwi.uni-regensburg.de
}

July 23, 2014

We thank Andreas Roider and the participants of the XIIth Symposium of the German Economic Association of Business Administration (Zurich, 2011), the $15^{\text {th }}$ Colloquium on Personnel Economics (Paderborn, 2012), and the 6th Doctoral Conference of the RGS (Bochum, 2013) for their constructive comments. All remaining errors are, of course, our own. 


\section{Introduction}

Standard principal-agent models often assume that the principal offers a 'take-it-or-leave-it' contract (Mookherjee and Ray, 2002). For most realworld problems, however, this approach does not seem to be appropriate. Many labour market situations are, rather, determined by some form of bargaining between workers and firms, with both parties holding some bargaining power. Therefore, a 'take-it-or-leave it' contract might be too restrictive to comprehensively model real labour market processes. Instead of that, introducing bargaining power brings the principal-agent framework closer to reality and allows some more important policy conclusions to be drawn.

Our paper contributes to the literature on bargaining in a moral hazard framework. Based on empirical and experimental evidence, we introduce the Kalai-Smorodinsky bargaining solution (henceforth KS solution) in a principal-agent model suffering from moral hazard. Comparing the KS bargaining outcome with the commonly used Nash solution, we find that the outcome of both bargaining solutions differ significantly although we assume risk-neutral firms and workers. This result is in contrast to bargaining with full information and risk-neutral players, where the familiar "split-thedifference' result is obtained. Moreover, we find that the allocation of the bargaining power determines the difference between both solutions. If the worker's bargaining power is relatively small, the Nash solution provides a more efficient outcome and induces more effort. If the worker's bargaining power is relatively high, however, the KS solution is more efficient. The critical value of the bargaining power, where the efficiency of the two solutions switches, depends on the elasticity of output with respect to effort and the precision of the firm's monitoring device.

Moreover, our paper aims at the normative question of whether and how government should intervene in the labour market. In a principal-agent framework, it is a well-known fact that inefficiencies occur due to moral hazard. The moral hazard problem requires the firm to offer an incentive contract to the worker. When workers are risk-neutral and have limited liability, the first-best contract will not be achieved. The firm faces a trade-off between offering a high-powered incentive scheme, leading to high effort but also high payments to the worker, or reducing effort by reducing the incen- 
tives and thus having lower payments for the worker. The optimal contract for the firm induces less effort than the first-best contract which maximises social welfare. To achieve this first-best solution, for example, the government may allocate the agent's bargaining power. ${ }^{1}$ We find that, apart from some extreme cases, the efficiency of the bargaining outcome can be improved by increasing the worker's bargaining power. This result is in some contrast to the literature on labour market negotiations which often finds that higher worker's bargaining power reduces employment and social welfare. We show that the change in the bargaining power to reach the efficient outcome has to be higher in the Nash than in the KS solution. On a more general level, our findings indicate that the choice of the specific bargaining solution is not innocuous but has important implications for workers' effort incentives and the efficiency of the labour contract.

The paper proceeds as follows. Section 2 provides a brief review of the related literature. Section 3 sets up the model. Section 4 analyses bargaining over an incentive contract if bargaining follows either the Nash or the KS solution. In this section, we also discuss the optimal allocation of the bargaining power. Section 5 concludes.

\section{Related Literature}

Our paper is related to two strands of the literature. First, the paper contributes to the literature on labour contracts in principal-agent models. Rather than a 'take-it-or-leave it' contract set by the principal, we assume that the principal and the agent can negotiate the contract terms. Pitchford (2002) shows that when agents have limited liability, the incentive contract depends on the bargaining power of the principal and the agent. Balkenborg (2001) introduces Nash bargaining in a moral hazard model with a

\footnotetext{
${ }^{1}$ To strengthen workers' bargaining power, the government can prohibit employer lockouts or limit the use of permanent replacements to enhance the costs of collective action for employers. To strengthen employers' bargaining power, the government could limit the possibilities of collective action by prohibiting secondary boycotts (Dau-Schmidt and Traynor, 2009). On a more general level, politics might also decide on the legal status of collective bargaining or to build workers' councils (Botero et al., 2004). These measures are decisive for collective bargaining power but also affect the bargaining power of single workers.
} 
risk-neutral principal and a wealth-constrained risk-neutral agent. Schmitz (2005) analyses how workplace surveillance affects the total welfare of an employment contract and whether a law against this surveillance may improve welfare. Extending the basic model, he also discusses the outcome when the contract agreed upon by employer and employee follows the Nash bargaining solution. Demougin and Helm (2006) analyse the impact of bargaining power on contracts in a moral hazard environment. They consider three different approaches: a standard principal-agent model, an alternating offer game and the Nash bargaining solution. Demougin and Helm (2006) find that all these frameworks lead to the same set of contracts. This set of contracts is achieved by varying the participants' discount factors (in the alternating offer game) or the participants' bargaining power (in the Nash solution). Moreover, Demougin and Helm (2009) use the Nash bargaining solution in a firm-worker framework suffering from moral hazard. Bental and Demougin (2010) model labour contract negotiations in a Nash bargaining game and derive the optimal bargaining power from the firm's, the worker's, and the social planner's viewpoint in an environment suffering from moral hazard and irreversible investment.

Second, and more specifically, our paper contributes to the literature on bargaining behaviour. When analysing bargaining processes in labour market frameworks, the Nash solution (Nash, 1950) is by far the most frequently used solution. Other solutions, such as that proposed by Kalai and Smorodinsky (1975), have mostly been ignored by the literature. This negligence is surprising, as both solution concepts are derived axiomatically and have game theoretic foundations (Binmore et al. (1986) for the Nash solution and Moulin (1984) for the KS solution). Moreover, an increasing number of empirical and experimental studies provide evidence in favour of the KS solution. Laroque and Salanié (2004) find that the KS solution offers a better description of the French labour market than the Nash solution does. Siegal and Fouraker (1960) and Nydegger and Owen (1974) provide experimental evidence that the Nash solution is an unreasonable model of pairwise negotiations as players make interpersonal comparisons of utility gains. Such behaviour cannot be captured by the Nash solution because of its independence of irrelevant alternatives axiom. The experimental results in Heckathorn (1978) and Dit- 
trich et al. (2011) support the KS model over the Nash model.

Only a few theoretical papers, however, build on this evidence and apply the KS solution in labour market models. Gerber and Upmann (2006) introduce the KS solution in a union-firm bargaining framework and point out that a higher disagreement payoff has negative effects on employment if bargaining follows the Nash solution. In the KS solution, however, increasing the disagreement payoff has ambiguous employment effects. Dittrich (2010) shows, in a similar union-firm framework, that the labour market effects of unemployment benefits and minimum wages in the Nash solution differ substantially from the effects if bargaining follows the KS solution. L'Haridon et al. (2013) introduce the KS solution into a matching framework and compare the bargaining outcome with the Nash solution. Dittrich and Knabe (2013) show, in a collective wage bargaining model, that spillover effects from minimum wages can be explained by the KS solution, but not by the Nash solution.

Summing up, these studies suggest that the choice of a specific bargaining solution should not be an arbitrary decision since preferring one bargaining solution over another might not only affect the labour market outcome but also the economic policy conclusions drawn from the model.

\section{The model}

We apply a standard principal-agent model with bargaining over an incentive contract (Demougin and Helm, 2009). Firms and workers are risk-neutral and workers are identical in their respective skills - that is, we abstract from possible adverse selection problems. Each representative firm is matched with one representative worker. After the matching process ends, the firm and the worker bargain over a labour contract. If bargaining is successful, there is a rent and both players receive their respective payoffs. If bargaining breaks down, both players receive an disagreement payoff which we assume to be zero for both players. If the worker is employed and undertakes effort $e \in[0,1]$, the output $v(e)=e^{\varepsilon}$, with $\varepsilon \in(0,1)$, is produced. Output, however, is not verifiable and thus not contractible. Effort is not observable by the firm, hence also not contractable, but it generates a binary signal 
$\sigma \in\{0,1\}$ serving as information for the firm if the worker undertakes effort. This signal is observable and verifiable, thus the parties can write a contract on it. The firm receives the favourable signal 1 with probability $p(e)=e^{\theta}$, with $\theta \in(0,1)$, and pays an incentive compatible bonus $B$ to the worker. As the probability for the favourable signal depends positively on the effort, making effort (and receiving the bonus) is worth it for the worker. However, effort causes costs $k(e)=c e$, with $c \geq 1 .^{2}$ From the worker's point of view, there is thus a trade-off between making effort or not. Furthermore, we assume that the worker is financially constrained and may not make any payments to the firm (limited liability). According to this financial constraint and the incentive compatibility, contracts are binary. The worker receives a fixed payment $F$ and, in addition, the bonus if $\sigma=1$. Total payments to the worker must not fall below zero. It is straightforward that this condition can be reduced to $F \geq 0$. Altogether we end up with the following payoff functions for the firm $(\Pi)$ and the worker $(U)$ :

$$
\begin{aligned}
& \Pi=e^{\varepsilon}-B e^{\theta}-F \\
& U=B e^{\theta}-c e+F .
\end{aligned}
$$

The parameter $\varepsilon$ reflects the elasticity of output with respect to effort. The parameter $\theta$ reflects the elasticity of the probability of observing the positive signal with respect to effort and can be interpreted as the precision of the firm's monitoring device (Bental and Demougin, 2010).

The rent, which is bargained over, depends on the worker's effort. Assuming that the players share the whole rent, the rent is equal to the sum of both payoffs and thus equals the social welfare $S(e)$ :

$$
S(e)=\Pi(e)+U(e)=e^{\varepsilon}-c e .
$$

The set of possible bargaining outcomes is determined by the Pareto frontier (PF). We obtain the PF by maximising firm's profit subject to the worker's incentive condition (5), the financial constraint (6) and the participation

\footnotetext{
${ }^{2}$ This assumption is necessary in order to assure that both $e$ and $p(e)$ will never be greater than 1.
} 
constraint $(7)^{3}$ :

$$
\begin{aligned}
\max _{e, F} \Pi & =e^{\varepsilon}-B e^{\theta}-F \\
\text { s.t. } B & =\frac{c}{\theta} e^{1-\theta} \\
F & \geq 0 \\
U & \geq \bar{U}
\end{aligned}
$$

The incentive condition (5) is derived from the first order condition of (2) and implicitly defines the worker's payoff-maximising effort given a bonus $B$.

For later analyses, it is useful to derive two distinct points on the PF. We first disregard the participation constraint (7) in order to derive the profitmaximising contract for the firm when the worker's participation constraint $\bar{U}$ is zero. ${ }^{4}$, i.e. we derive the contract the firm would offer in a 'take-it-orleave-it' situation. As the financial constraint (6) holds, the firm sets $F=0$ and chooses the profit-maximising effort (Demougin and Helm, 2009). ${ }^{5}$ We derive the firm's optimal effort level $e^{* *}$ maximising (4) subject to (5) and (6):

$$
e^{* *}=\left(\frac{\varepsilon \theta}{c}\right)^{\frac{1}{1-\varepsilon}},
$$

with $\Pi\left(e^{* *}\right)$ denoting the firm's maximum profit. Given $e^{* *}$, the worker's payoff is $U^{* *}=\left(\frac{1}{\theta}-1\right) c e^{* *}>0 .{ }^{6}$ It is straightforward that the PF starts at a level $U>0$, because every payoff $U<U^{* *}$ reduces the worker's payoff without increasing the firm's profit. Hence, each $U<U^{* *}$ is inefficient and is therefore not part of the PF. Second, we calculate the effort $e^{*}$ which maximises the social welfare. Differentiating (3) with respect to $e$ yields the socially optimal effort level $e^{*}$ :

$$
e^{*}=\left(\frac{\varepsilon}{c}\right)^{\frac{1}{1-\varepsilon}}
$$

\footnotetext{
${ }^{3}$ The detailed derivation of the PF can be found in the Appendix.

${ }^{4}$ We show later that the worker's payoff will be positive even without the participation constraint (7).

${ }^{5}$ The firm cannot directly choose effort but can offer the worker an incentive contract inducing the optimal effort from the firm's viewpoint.

${ }^{6}$ This condition implies that the worker's payoff is greater than zero for every effort level. Therefore, the worker will never receive a payment lower or equal to zero as long as the financial constraint $F \geq 0$ holds.
} 
and the corresponding worker's payoff $U^{*}=\left(\frac{1}{\theta}-1\right) c e^{*}$. Comparing (8) and (9) reveals that $e^{*}>e^{* *}$ and $U^{*}>U^{* *}$. Using (9) and (1), we derive the firm's payoff in the social optimum:

$$
\Pi^{*}=c\left(\frac{\varepsilon}{c}\right)^{\frac{1}{1-\varepsilon}}\left(\frac{1}{\varepsilon}-\frac{1}{\theta}\right)\left\{\begin{array}{lll}
>0 & \text { if } & \varepsilon<\theta \\
=0 & \text { if } & \varepsilon=\theta \\
<0 & \text { if } & \varepsilon>\theta
\end{array}\right.
$$

That is, the social efficient effort cannot be achieved if $\varepsilon>\theta$, since the firm's payoff would be negative and lower than the disagreement payoff. The social efficient effort level would be achievable even with $\varepsilon>\theta$ if a negative fixed payment $F$ is possible. The principal would then be compensated by this payment from the agent. This, however, is excluded by the limited liability assumption. We therefore restrict our analysis to $\varepsilon \leq \theta$.

\section{Bargaining over the contract}

So far, we have derived the firm's optimal contract in a take-it-or-leaveit situation, as well as the socially optimal contract maximising the social welfare. We now assume that the firm and the worker bargain over the effort level and will agree on a contract on the PF.

\section{The Nash bargaining solution}

We first analyse the bargaining outcome of the Nash solution. Nash (1950) specifies four axioms - Pareto efficiency, invariance to equivalent utility representations, symmetry, and independence of irrelevant alternatives - and shows that there is one bargaining solution satisfying these axioms. The solution requires that effort is chosen so as to maximise the weighted product of each agent's net return from reaching an agreement. The Nash bargaining solution solves the following maximisation problem:

$$
\begin{aligned}
\max _{e} N & =\left(e^{\varepsilon}-\frac{c}{\theta} e\right)^{1-\alpha}\left(\frac{c}{\theta} e-c e\right)^{\alpha} \\
\text { s.t. } e & \leq e^{*}
\end{aligned}
$$


where $N$ is the value of the weighted Nash product. We assume that the worker and the firm may have different bargaining strengths (Harsanyi and Selten, 1972). We denote worker's and firm's bargaining power by $\alpha \in[0,1]$ and $1-\alpha$, respectively. In many countries, this bargaining power is determined by labour market institutions and may be influenced, directly or indirectly, by the government. The government can affect the bargaining power by, e.g., prohibiting employer lockouts, limiting the use of permanent replacements or limiting the possibilities of collective action. ${ }^{7}$ Thus, bargaining power is exogenous in our model and does not depend on the specific bargaining solution, but can be affected by government regulation.

We restrict our analysis to $F=0$, as the agents bargain over the effort level, which is not linked to the fixed payment. Only if the agents (hypothetically) agree on an effort level greater than the social efficient effort, condition (12) would be binding and the fixed payment would be greater than zero. Effort, however, remains at $e^{*}$.

Solving the maximisation problem (11), we derive the effort level in the Nash solution, $e^{N}$ :

$$
e^{N}=\left\{\begin{array}{lll}
{\left[\frac{\theta}{c}(\alpha+\varepsilon(1-\alpha))\right]^{\frac{1}{1-\varepsilon}}} & \text { if } \quad \alpha \leq \frac{\varepsilon(1-\theta)}{\theta(1-\varepsilon)} \\
e^{*} & \text { if } \quad \alpha>\frac{\varepsilon(1-\theta)}{\theta(1-\varepsilon)}
\end{array}\right.
$$

In a next step, we discuss the allocation of bargaining power. The government is able to affect the labour market outcome and can, at least to some extent, improve the efficiency of labour contracts. The welfare-maximising government takes the first-best effort $e^{*}$ as a reference point and adjusts the bargaining power in order to derive the efficient outcome. Calculating the bargaining power that maximises the social welfare and yields the socially optimal effort in the Nash solution, $\alpha^{N^{*}}$, we use (9) together with (13) and solve the equation $e^{*}=e^{N}(\alpha)$ for $\alpha$ :

$$
\alpha^{N^{*}}=\frac{\varepsilon(1-\theta)}{\theta(1-\varepsilon)} .
$$

\footnotetext{
${ }^{7}$ For an overview of possible measures of labour regulation see Botero et al. (2004).
} 
It is easy to see that $\alpha^{N^{*}}<(=) 1$, if $\varepsilon<(=) \theta \cdot{ }^{8}$ If $\alpha>\alpha^{N^{*}}$, it is straightforward from (14) and (15) that effort will remain at $e^{*}$. In such a situation, the firm pays the bonus $B$ to induce $e^{*}$ and additionally pays a fixed payment $F>0$.

\section{The Kalai-Smorodinsky bargaining solution}

In this section, we analyse the bargained contract if bargaining follows the $\mathrm{KS}$ solution. The plausibility of Nash's independence of irrelevant alternatives axiom, which states that eliminating or adding an apparently irrelevant alternative should not change the solution, has received strong criticism (Luce and Raiffa, 1957). Kalai and Smorodinsky (1975) replace this axiom with the property of individual monotonicity. This axiom implies that the players must not suffer from an enlargement of the bargaining set that leaves the maximum utilities attainable by both players unchanged. Based on this axiom, Kalai and Smorodinsky (1975) suggest a solution where both parties make equal proportional concessions from their respective favoured points. The KS solution can be described by the KS curve:

$$
\alpha \frac{\Pi}{\Pi^{+}}=(1-\alpha) \frac{U}{U^{+}},
$$

where $\Pi$ and $U$ denote the agents' payoffs and $\Pi^{+}$and $U^{+}$the agents' bliss points, respectively. The bliss points are the best obtainable payoffs for an agent given that the other agent receives at least its disagreement payoff, which is assumed to be zero in our model. In order to account for different bargaining strengths, we apply the asymmetric axiomatic solution proposed by Dubra (2001) sucht that $\alpha$ and $1-\alpha$ denote worker's and firm's bargaining power, respectively. That is, $\alpha$ reflects the worker's exogenously given bargaining strength in both solutions (Thomson, 1994). ${ }^{9}$

To solve the KS bargaining problem, we first calculate the agents' bliss

\footnotetext{
${ }^{8}$ If $\varepsilon>\theta$, the socially optimal bargaining power would be greater than 1 . However, this case cannot be achieved since $\alpha \in[0,1]$ and, thus, shows again why we restrict our analysis to $\varepsilon \leq \theta$.

${ }^{9}$ Similarly, the union-firm bargaining models in Gerber and Upmann (2006) and Dittrich (2010) use a parameter which reflects the same bargaining power in the Nash and the KS solution.
} 
points. The firm would choose $B$ to maximise its own payoff, given the worker receives at least a payoff of zero. Again, the worker's incentive condition $(5)^{10}$ as well as the financial constraint (6) hold. Thus, we maximise firm's profit (1) subject to the constraints (5) and (6). The contract derived is the same as in a take-it-or-leave-it situation with effort $e^{* *}$ (see (8)). Hence, the firm's bliss point is given by

$$
\Pi^{+}=\Pi\left(e^{* *}\right)=(1-\varepsilon)\left(\frac{\theta \varepsilon}{c}\right)^{\frac{\varepsilon}{1-\varepsilon}} .
$$

The worker's bliss point is the best payoff the worker can achieve. The worker chooses effort as response to the best bonus $B$ he could receive, given the firm's payoff (1) is at least zero. The zero-profit condition for the firm holds with equality, since any positive value of $\Pi$ given a combination of effort and bonus could be extracted by the worker by means of the fixed payment $F$. Rearranging (1) to get the zero-profit condition gives $F=e^{\varepsilon}-B e^{\theta}$. Substituting into $(2)$ yields $U(e)=e^{\varepsilon}-c e$, i.e. the social welfare $S(e)$ given by (3). Maximising yields the worker's bliss point:

$$
U^{+}=(1-\varepsilon)\left(\frac{\varepsilon}{c}\right)^{\frac{\varepsilon}{1-\varepsilon}}
$$

Substituting the agents' bliss points (16) and (17) into (15), we end up with the following KS curve:

$$
\begin{aligned}
\frac{e^{\varepsilon-1}-\frac{c}{\theta}}{\theta^{\frac{\varepsilon}{1-\varepsilon}}} & =\frac{1-\alpha}{\alpha} c\left(\frac{1}{\theta}-1\right) \\
\text { s.t. } \quad e & \leq e^{*} .
\end{aligned}
$$

Condition (19) allows to restrict our analysis to the case $F=0$. If the effort derived in the KS solution is (hypothetically) greater than the socially optimal effort $e^{*}$, condition (19) holds and $F>0$. Effort, however, remains at $e^{*}$.

\footnotetext{
${ }^{10}$ Otherwise, the firm would maximise output minus costs and extract the entire rent. However, due to the moral hazard problem, the firm cannot simply implement the social welfare maximising effort level. The firm's best obtainable contract is achieved by maximising the payoff given the worker's incentive condition.
} 
Solving (18) for $e$ with respect to (19) yields:

$$
e^{K S}= \begin{cases}{\left[\frac{\theta}{c} \frac{\alpha}{(1-\alpha) \mu+\alpha}\right]^{\frac{1}{1-\varepsilon}}} & \text { if } \quad \alpha \leq \frac{\mu \varepsilon}{\mu \varepsilon+\theta-\varepsilon} \\ e^{*} & \text { if } \quad \alpha>\frac{\mu \varepsilon}{\mu \varepsilon+\theta-\varepsilon} .\end{cases}
$$

with $\mu=(1-\theta) \theta^{\frac{\varepsilon}{1-\varepsilon}} \in(0,1)$.

Figure 1 pictures the outcomes of both bargaining solutions. The Nash bargaining solution is given by the highest Nash product $(N)$ which is tangent to the PF. In general, the Nash solution is located on the PF between points $\mathrm{A}$ and $\mathrm{B}$, depending on $\alpha$. The lower bound $\mathrm{A}$, which would be the bargaining outcome if $\alpha=0$, is determined by the 'take-it-or-leave-it' contract. The upper bound B is determined by the firm's disagreement point and the corresponding worker's utility. The larger $\alpha$, the more the solution is located at the right on the PF implying a higher payoff for the worker. Consequently, also effort increases until $U^{*}$ is reached. Beyond that point, effort remains at the efficient level. For ease of exposition, Figure 1 shows a specific Nash outcome for $\alpha=0.5$ (D).

The KS solution is given by the intersection of the KS curve and the PF. The KS curve connects the disagreement payoff, which we assumed to be zero, with the bliss point C. A specific KS outcome for $\alpha=0.5$ is reflected by E. As in the Nash solution, both the worker's payoff and effort increase in $\alpha$. Until effort reaches the first-best level (at $U^{*}$ ), the efficiency of the contract increases in the worker's bargaining power. Moreover, two corner solutions are represented by $\mathrm{A}(\alpha=0)$ and $\mathrm{B}(\alpha=1)$, where the solution is equal to the bliss point, respectively.

To find the bargaining power which yields the socially optimal effort in the KS bargaining solution, $\alpha^{K S^{*}}$, we use (9) together with (20) and solve the equation $e^{*}=e^{K S}(\alpha)$ for $\alpha$ :

$$
\alpha^{K S^{*}}=\frac{\mu \varepsilon}{\mu \varepsilon+\theta-\varepsilon} .
$$

It is straightforward that $\alpha^{K S^{*}}<(=) 1$, if $\varepsilon<(=) \theta$. If $\alpha>\alpha^{K S^{*}}$, we find from (20) and (21) that effort will remain at $e^{*}$, the firm pays $B$ to induce $e^{*}$ and additionally pays $F>0$. 


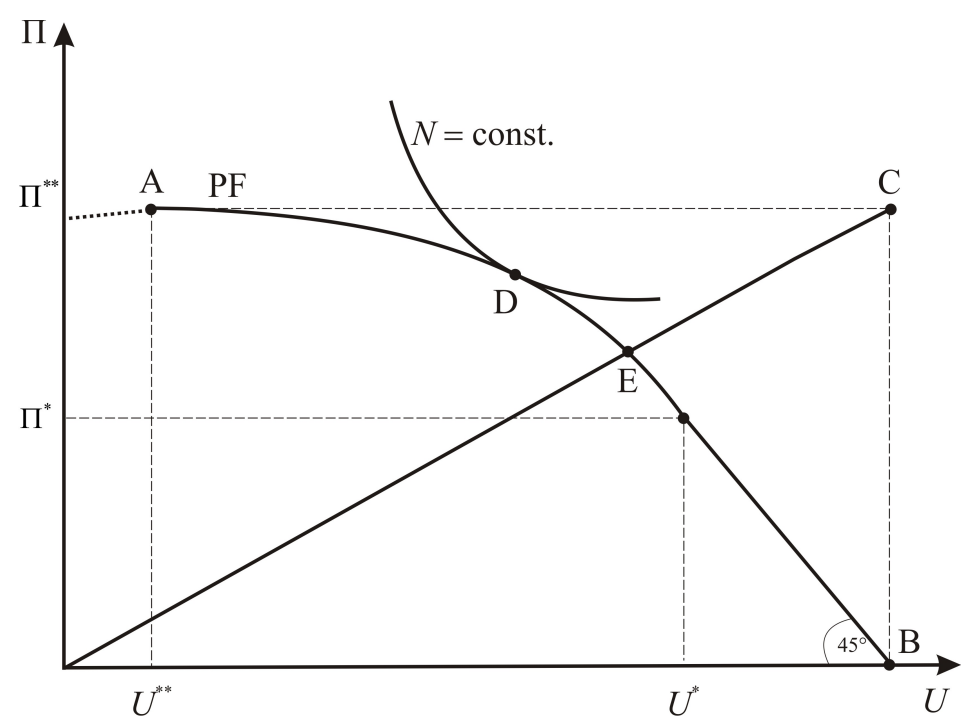

Figure 1: The Nash and KS bargaining solutions.

\section{Comparing the Nash and the Kalai-Smorodinsky bargaining solu- tions}

We now analyse the efficiency of both bargaining outcomes. Since in our moral hazard problem, efficiency is linked to effort undertaken by the worker, we examine which bargaining solution induces more effort for any given bargaining power.

Comparing the respective optimal bargaining power in both solutions gives our first result.

Proposition 1 If the worker's bargaining power does not induce the socially optimal effort $e^{*}$, the social planner increases $\alpha$ such that the worker undertakes $e^{*}$. To achieve the socially optimal effort, for any given $\alpha$, this increase has to be higher in the Nash solution than in the KS solution.

We can prove this result by comparing the optimal bargaining power in the Nash and KS solutions, (14) and (21). As $\mu=(1-\theta) \theta^{\frac{\varepsilon}{1-\varepsilon}}<1-\theta$, we have that $\alpha^{K S^{*}}<\alpha^{N^{*}}$. That is, the KS solution yields the socially efficient effort with a smaller $\alpha$. Consequently, to obtain $e^{*}$, worker's bargaining power should be raised less in the KS than in the Nash solution.

Our next result shows the relative efficiency of the two bargaining solu- 
tions.

Proposition 2 Whether effort is higher in the Nash or in the KS solution depends on a critical value of the worker's bargaining power, $\widetilde{\alpha}_{1}$. For any given bargaining power $\alpha$, the respective effort resulting from Nash and KS bargaining is related to the critical value and the socially optimal effort as follows:

$$
\begin{aligned}
& e^{N}\left\{\begin{array}{l}
> \\
= \\
<
\end{array}\right\} e^{K S} \text { and } e^{N}, e^{K S}<e^{*} \quad \text { if }\left\{\begin{array}{l}
\alpha<\widetilde{\alpha}_{1} \\
\alpha=\widetilde{\alpha}_{1} \\
\alpha^{K S^{*}}>\alpha>\widetilde{\alpha}_{1}
\end{array}\right. \\
& e^{N}<e^{K S}=e^{*} \quad \text { if } \quad \alpha^{K S^{*}} \leq \alpha<\alpha^{N^{*}} \\
& e^{N}=e^{K S}=e^{*} \quad \text { if } \alpha \geq \alpha^{N^{*}} \text {. }
\end{aligned}
$$

Proof. Equalising the effort levels derived in both bargaining solutions, (13) and (20), yields the following condition implicitly defining the critical value of $\alpha$, for which both solutions induce the same effort:

$$
\alpha+(1-\alpha) \varepsilon=\frac{\alpha}{\alpha+(1-\alpha) \mu} .
$$

Reformulating (22) leads to a quadratic equation representing $e^{N}-e^{K S}=$ 0 :

$$
(1-\mu)(1-\varepsilon) \alpha^{2}-((1-\mu)(1-\varepsilon)+\mu \varepsilon) \alpha+\mu \varepsilon=0 .
$$

Solving (24) for yields the critical values

$$
\widetilde{\alpha}_{1}=\frac{\mu \varepsilon}{(1-\mu)(1-\varepsilon)}
$$

and $\widetilde{\alpha}_{2}=1 .{ }^{11}$ Comparing (21) and (24), and using Proposition 1, we find that $\widetilde{\alpha}_{1}<\alpha^{K S^{*}}<\alpha^{N^{*}}$. For any $\alpha<(>) \widetilde{\alpha}_{1}$, we thus have $e^{N}>(<) e^{K S}{ }^{12}$ For any $\alpha<\widetilde{\alpha}_{1}$, the Nash solution induces more effort and leads to a more

${ }^{11}$ This is easy to see if we reformulate $(24)$ as $\alpha^{2}-(1+z) \alpha+z=0$, with $z=\frac{\mu \varepsilon}{(1-\mu)(1-\varepsilon)}$. Solving for $\alpha$ gives $\alpha_{1}=z$ and $\alpha_{2}=1$.

${ }^{12}$ In (23) we do not take into account the constraints (13) and (20). If these conditions become binding, there might exist some $\alpha>\widetilde{\alpha}_{1}$ for which both bargaining solutions yield the same effort $e^{*}$. 
efficient contract. When the worker's bargaining power exceeds the critical value $\widetilde{\alpha}_{1}$, however, the KS solution is more efficient. If the KS outcome, but not the Nash outcome, is at the social optimum $\left(\alpha^{K S^{*}} \leq \alpha<\alpha^{N^{*}}\right)$, an increase in worker's bargaining power will only increase effort in the Nash solution. If bargaining power is such that $\alpha^{K S^{*}}<\alpha^{N^{*}} \leq \alpha$, both solutions are socially optimal and, consequently, allocating the bargaining power does not increase welfare.

Figure 2 pictures these results.

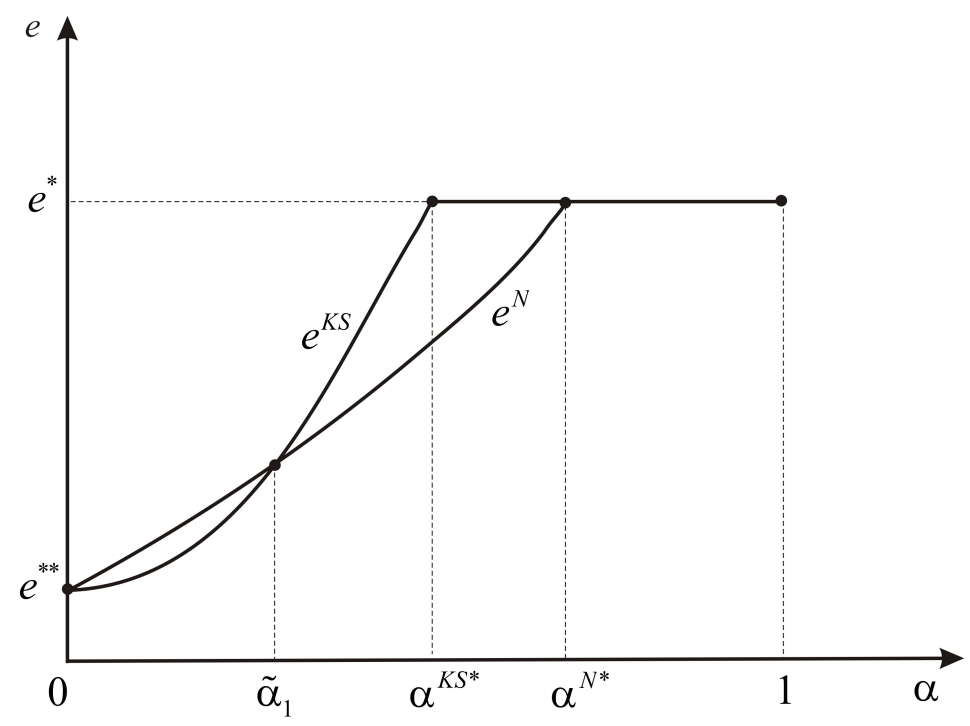

Figure 2: Effort and worker's bargaining power in the Nash and the KS solutions.

Proposition 3 If the firm and the worker have equal bargaining power such that $\alpha=0.5<\alpha^{N^{*}}$, the KS solution induces more effort than the Nash solution.

Proof. Examining (24), we find that $\widetilde{\alpha}_{1}$ has its maximum value when both $\varepsilon \rightarrow 1$ and $\theta \rightarrow 1$. Reformulating (24) gives the limit value for $\widetilde{\alpha}_{1}$ :

$$
\lim _{\varepsilon \rightarrow 1, \theta \rightarrow 1} \frac{1}{\frac{\varepsilon-1}{\varepsilon}+\frac{1-\varepsilon}{\varepsilon(1-\theta)} \theta^{\frac{\varepsilon}{\varepsilon-1}}}=\theta^{\frac{\varepsilon}{1-\varepsilon}} \approx 0.37 .
$$

In the denominator in (25) it holds that $\frac{\varepsilon-1}{\varepsilon} \rightarrow 0$ and $\frac{1-\varepsilon}{\varepsilon(1-\theta)} \rightarrow 1$. Thus, $\widetilde{\alpha}_{1}$ cannot exceed the critical value 0.37 . From Proposition 2 it follows that 
the KS solution is more efficient if both agents have equal bargaining power, that is if $\alpha=0.5>\widetilde{\alpha}_{1}$. This result, however, only holds for $\alpha^{N^{*}}>0.5$. If $\alpha=0.5>\widetilde{\alpha}_{1}$ but $\alpha^{N^{*}} \leq 0.5$, both bargaining solutions induce the same, socially optimal effort.

\section{Conclusion}

We analysed the KS solution in a moral hazard framework with bilateral bargaining over an incentive contract. A comparison with the Nash solution shows that worker's and firm's bargaining power play a crucial role in answering the question of whether both solutions yield the same effort or not. In most cases, the Nash and KS solutions yield different outcomes. If the worker's bargaining power is relatively small, the Nash solution provides a more efficient outcome inducing more effort. If the worker's bargaining power is relatively high, however, the KS solution is more efficient. The critical value of the bargaining power, where the efficiency of the two solutions changes, depends on the elasticity of output with respect to effort and the precision of the firm's monitoring device. Moreover, our results imply that raising the worker's bargaining power can improve efficiency. Allocation of the bargaining power by a social planner can mitigate the moral hazard frictions arising from an incentive compatible contract. Such an intervention should be stronger in the Nash solution than in the KS solution.

Our findings suggest that the choice of the specific bargaining solution in principal-agent models is not innocuous. The often applied Nash solution might be easier to work than its alternatives. However, the Nash solution is not able to explain some important findings from the empirical and experimental literature due to its independence of irrelevant alternatives axiom. Instead, the KS solution has the potential to extend our understanding of wage determination processes in moral hazard frameworks. As we show, the outcome in both solutions might differ significantly. With full information and risk neutral bargaining partners, the Nash and the KS solution yield the same type of contract. However, in an empirically more relevant model with incomplete information, both solutions lead to different contracts and, consequently, to different economic implications. On a more general level, 
our findings indicate that the choice of the specific bargaining solution in modelling labour markets suffering from moral hazard is an important question and that one has to consider more carefully which bargaining solution to apply.

\section{Appendix}

In Section 3, we derived $e^{* *}$ and the respective payoffs without the worker's participation constraint (7). Reintroducing this constraint and letting $\bar{U}$ grow step by step yields the rest of the PF. To increase the worker's payoff, the firm must offer a better contract to the worker. Starting at $U^{* *}$, the corresponding effort $e^{* *}$ is lower than the efficient effort $e^{*}$. To increase the worker's payoff it is therefore more efficient to increase the bonus instead of increasing the fixed payment, because $B$ induces more effort. This is welfareincreasing until effort reaches the first-best level $e^{*}$. From $U^{*}$ onwards it is efficient to increase the worker's payoff by increasing the fixed payment $F$, while the effort remains at its efficient level.

Analytically, the slope of the PF is given by

$$
\frac{d \Pi}{d U}=\frac{\partial \Pi / \partial e}{\partial U / \partial e}=\frac{\frac{c}{\theta}-\varepsilon e^{\varepsilon-1}}{\frac{c}{\theta}-c}\left\{\begin{array}{lll}
=0 & \text { if } \quad e=e^{* *} \\
\in(-1,0) & \text { if } \quad e^{* *}<e<e^{*} \\
=-1 & \text { if } \quad e \geq e^{*}
\end{array}\right.
$$

For $e=e^{* *}$, the numerator in (26) equals zero implying that the $\mathrm{PF}$ has slope 0 at the firm's profit-maximising effort level. The second term in the numerator reflects the marginal output with respect to effort. As long as the socially optimal effort is not achieved, the marginal output exceeds the marginal costs of effort. Therefore the slope of the PF is between 0 and -1 until effort reaches the socially optimal level. At this effort $\left(e^{*}\right)$ the slope of the $\mathrm{PF}$ is -1 . From this point there are only lump-sum transfers from the firm to the worker by increasing $F$. That is, the PF's slope stays at -1 for every effort level greater than $e^{*}$.

Figure 3 pictures the PF. The dashed segment of the curve is not part of 
the PF, since all contracts located there are inefficient (Demougin and Helm, 2009).

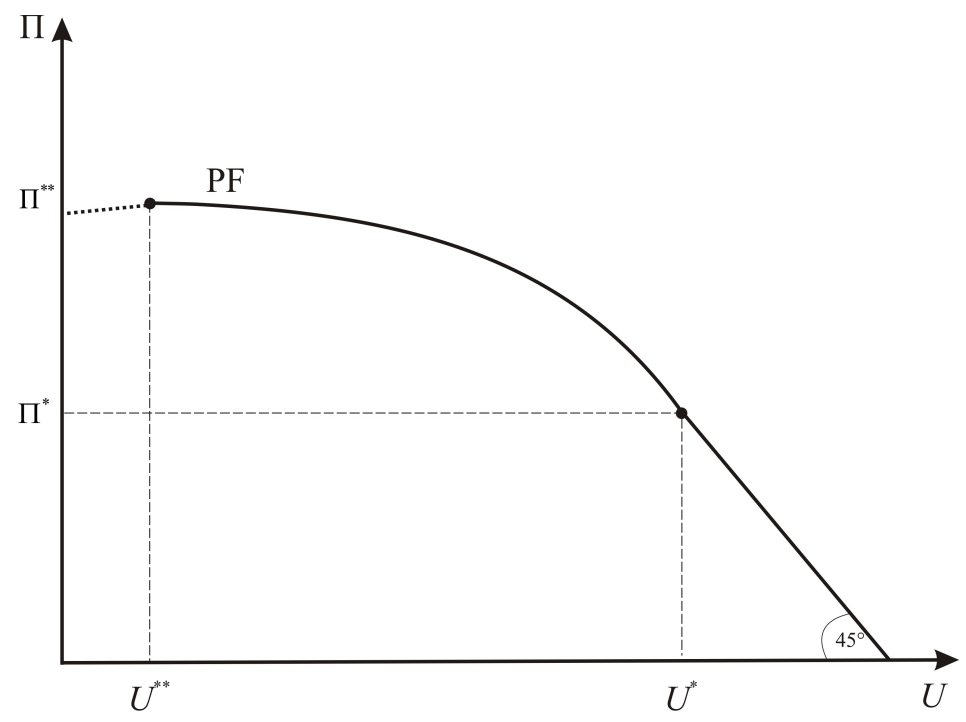

Figure 3: The Pareto frontier.

\section{References}

Balkenborg, D. (2001). How liable should a lender be? The case of judgmentproof firms and environmental risk: Comment. American Economic Review 91(3), 731-738.

Bental, B. and D. Demougin (2010). Declining labor shares and bargaining power: An institutional explanation. Journal of Macroeconomics 32(1), $443-456$.

Binmore, K., A. Rubinstein, and A. Wolinsky (1986). The Nash bargaining solution in economic modelling. RAND Journal of Economics 17(2), 176188.

Botero, J., S. Djankov, R. La Porta, F. Lopez-de-Silanes, and A. Shleifer (2004). The regulation of labor. Quarterly Journal of Economics 119(4), 1339-1382. 
Dau-Schmidt, K. and A. Traynor (2009). Regulating unions and collective bargaining. In K. Dau-Schmidt, S. Harris, and O. Lobel (Eds.), Labor and Employment Law and Economics, pp. 96-128. Cheltenham: Edward Elgar.

Demougin, D. and C. Helm (2006). Moral hazard and bargaining power. German Economic Review 7(4), 463-470.

Demougin, D. and C. Helm (2009). Incentive contracts and efficient unemployment benefits. CESifo Working Paper 2670.

Dittrich, M. (2010). Minimum wages and unemployment benefits in a unionised economy: A game-theoretic approach. Annals of Economics and Finance 11(2), 209-229.

Dittrich, M. and A. Knabe (2013). Spillover effects of minimum wages under union wage bargaining. Journal of Institutional and Theoretical Economics $169(3)$, 506-518.

Dittrich, M., A. Knabe, and K. Leipold (2011). Spillover effects of minimum wages: Theory and experimental evidence. CESifo Working Paper 3576.

Dubra, J. (2001). An asymmetric Kalai-Smorodinsky solution. Economics Letters 73(2), 131-136.

Gerber, A. and T. Upmann (2006). Bargaining solutions at work: Qualitative differences in policy implications. Mathematical Social Sciences 52(2), $162-175$.

Harsanyi, J. C. and R. Selten (1972). A generalized Nash solution for twoperson bargaining games with incomplete information. Management Science 18(5), 80-106.

Heckathorn, D. (1978). A paradigm for bargaining and a test of two bargaining models. Behavioral Science 23(2), 73-85.

Kalai, E. and M. Smorodinsky (1975). Other solutions to Nash's bargaining problem. Econometrica 43(3), 513-518.

Laroque, G. and B. Salanié (2004). Salaire minimum et emploie en présence de négociations salariales. Annales d'Economie et de Statistique 73, 1-22. 
L'Haridon, O., F. Malherbet, and S. Perez-Duarte (2013). Does bargaining matter in the small firm's matching model? Labour Economics 21, 42-58.

Luce, D. and H. Raiffa (1957). Games and decisions. Introduction and critical survey. New York: Wiley.

Mookherjee, D. and D. Ray (2002). Contractual structure and wealth accumulation. American Economic Review 92(4), 818-849.

Moulin, H. (1984). Implementing the Kalai-Smorodinsky bargaining solution. Journal of Economic Theory 33(1), 32-45.

Nash, J. F. (1950). The bargaining problem. Econometrica 18(2), 155-162.

Nydegger, R. V. and G. Owen (1974). Two-person bargaining: An experimental test of the Nash axioms. International Journal of Game Theory 3(4), 239-249.

Pitchford, R. (2002). Moral hazard and limited liability: The real effects of contract bargaining. Economics Letters 61(2), 251-259.

Schmitz, P. (2005). Workplace surveillance, privacy protection and efficiency wages. Labour Economics 12(6), 727-738.

Siegal, S. and L. Fouraker (1960). Bargaining and group decision making: Experiments in bilateral monopoly. New York: McGraw-Hill.

Thomson, W. (1994). Cooperative models of bargaining. In R. Aumann and S. Hart (Eds.), Handbook of Game Theory with Economic Applications, Volume 2, pp. 1237-1284. Amsterdam: North Holland. 